\title{
¿Un modelo de urbanización? la ciudad de México de finales del siglo XIX*
}

Hira de Gortari Rabiela

\begin{abstract}
URBE. Fin s. XIX. Tom. del lat. urbs, urbis ciudad. Deriv. Lihano, $2^{\prime \prime}$ cuarto s. Xv: urbanizar, fins. s. XIX... Urbanizar: hacer urbano y cortés a uno... Convertir en ciudad o población una porción de terreno o prepararlo para ello.'
\end{abstract}

In los últimos meses nos hemos estado preguntando, cada vez con mayor inquietud, acerca del futuro de nuestra capital, no solamente como una cuestión académica, sino -creo no exagerarcomo un asunto de sobrevivencia.

Como cualquier ciudadano, sostengo opiniones acerca de lo que se debe hacer respecto a la ciudad, pero profesionalmente tengo una forma de inquirir sobre el futuro, y es retornar al pasado para encontrar algunas respuestas satisfactorias; léase entonces como una interrogación histórica sobre el acontecer citadino.

No pretendo agotar el tema, pero sí esclarecer algunas de las tribulaciones que nos abruman; una de las más importantes, me parece, es indagar cuándo la urbanización de la capital inició un ritmo prácticamente incontrolable. Este fenómeno lo considero contemporáneo -de los últimos veinticinco años-, aunque no dejo de interrogarme sobre su origen, el cual no es tan reciente y que puede localizarse cronológicamente a finales del siglo pasado, y al cual me referiré.

Esta última aseveración se basa en la certidumbre de que en la restauración de la República y en el régimen encabezado por el presidente Diaz, se cimentaron algunas características fundamentales del sistema urbano y, particularmente, el colocar a la capital como su pieza estratégica.

En el ensayo que presento, trataré exclusivamente aquellas tendencias y decisiones que en el proceso urbano contemporáneo se han mantenido y cuya importancia incluso se ha acrecentado. Estas. pese a la ruptura revolucionaria, conservaron la capital como el principal centro urbano y reforzaron su peso político y económico.

La perspectiva que podemos formarnos de la historia de la ciudad como capital política, contemplada desde el presente, es inte-

\footnotetext{
* Una primera versión fue presentada en Oaxaca en la VII Reunión de Historiadores Mexicano-norteamericanos. en octubre de 1985.

1 Joan Corominas. Breve diccionario etimologico de la lengua castellana. Madrid. Editorial Gredos. 1983, (3a. edición muy revisada y mejorada); Julio Casares. Diccionario idcologico de la lengua española. Barcelona, Editorial Gustavo Gili, 1963 (2a. edición puesta al día).
} 
resante pues se puede apreciar cómo se ha conformado en parte nuestro sistema político.

El desempeño de la ciudad de México en tanto que capital nacional, es una realidad histórica permanente y excepcional, dado que es la única en América Latina surgida de una tradición urbana indígena, mantenida durante el dominio colonial y confirmada en el México independiente - no sin interrupciones- y hasta la fecha, como sede del poder nacional. ${ }^{2}$

El albergar al poder político, fundamental en la mayor parte de la historia de nuestro país, la convierte en un lugar estratégico del territorio. En el periodo nacional, la ciudad de México fue confirmada como capital de la nueva nación y formó parte del recién creado Distrito Federal según se estipulaba en la Constitución de 1824 , donde se dividía a la República en 19 estados, 5 territorios y un Distrito Federal. ${ }^{3}$

Llegar al acuerdo de establecer la capital en el mismo lugar que la virreinal, supuso discusiones arduas en el seno del Congreso Constituyente, pues dividió a los diputados a favor y en contra; estos últimos no se oponían a contar con una capital y formar un Distrito Federal donde se estableciera, sino que para dichos diputados, la antigua capital virreinal debería pasar a ser solamente la cabecera de un estado de la federación y la de la nación debería cambiar de sede. Su opinión no fue escuchada y México se convirtió en la capital. ${ }^{4}$

La decisión tomada en el Congreso trajo consigo desde el origen de la federación una duplicidad de funciones a la ciudad de México, dado que era la capital de la nación y por tanto sede del poder federal y a la vez, por su carácter de ciudad le correspondia un ayuntamiento con sus respectivas autoridades constituidas.

Tal dualidad fue preocupación frecuente de las autoridades locales y nacionales, pues era evidente en circunstancias de enfrentamiento y conflicto. En las discusiones en el Congreso Constituyente de 1856-1857, la necesidad de cambiar la capital volvió a plantearse; entre los argumentos más arraigados estaba el temor de posibles dificultades en el terreno de las prerrogativas entre los poderes que coexistian en la ciudad, así como la urgencia de contar con una nueva capital republicana. Los argumentos a favor del cambio convencieron y tuvieron mayoría $\mathrm{y}$, en la Constitución promulgada en 1857, en el artículo 46, se estableció que: "El Estado del Valle de México se formará del territorio que en la actualidad comprende el Distrito Federal; pero la erección sólo tendrá efecto cuando los supremos poderes federales se trasladen a otro lugar."

2 Claude Bataillon, Villes et campagnes dans la région de Mexico, París, Ediciones Anthropos, 1917, p. 4.

${ }^{3}$ Juan N. Rodriguez de San Miguel, Pandectas hispano-mexicanas, Introducción de Maria del Refugio González, México, UNAM, Instituto de Investigaciones Juridicas, 1980, t. II, p. 904.

4 Actas Constitucionales Mexicanas (1821-1824). Diario de las sesiones del Congreso Constituyente de la Federación Mexicana. Sesión del mes de junio y julio de 1824, México, UNAM, Instituto de Investigaciones Juridicas, 1981, t. X, sesiones de los días 22 y 23 de julio de 1824 .

' Constitución Federal de los Estados Unidos Mexicanos. Sancionada y jurada por el Congreso General Constituyente el dia 5 de febrero de 1857. México, Imprenta de Ignacio Cumplido, 1857, p. 42. 
El carácter provisional de la ciudad de México como capital, según se estipulaba en la Constitución de 1857 , subsistió varias décadas, por lo que existía jurídicamente una situación anómala que se trató de corregir (aunque no respetando el texto constitucional) con un decreto del Ejecutivo promulgado en 1900, gracias a la autorización que previamente le habia otorgado el Congreso para reformar la organización política y municipal del Distrito y los territorios federales.

En uso de estas facultades, el Ejecutivo expidió en 1903 una "Ley de "organización política y municipal del Distrito Federal"; en lo esencial, la ley recogía decretos anteriores sobre los límites y división interna del Distrito, compuesto por trece municipalidades, entre otras, la de México. A su vez, la ley fue acompañada de un "Decreto de incorporación de impuestos y rentas del Distrito y sus municipalidades a la secretaría de Hacienda". 6

En cuanto a su gobierno y administración, el Distrito Federal, en el orden legislativo, se regiría desde la promulgación de la ley por las leyes que dictara el Congreso para su régimen interior; en el aspecto administrativo, político y municipal, dependía del Ejecutivo Federal por conducto de la Secretaria de Gobernación. Para dirigir la política y la administración municipal, el Ejecutivo nombraría a un gobernador, un presidente del Consejo Superior de Salubridad y un director general de Obras Públicas, todos dependientes de la Secretaría de Gobernación.

No acatar a la letra el artículo del 57 referente al traslado de la capital y a la formación del estado del Valle de México, y manteniendo de facto a la ciudad de México como capital, fue una violación a la Constitución que se trató de aliviar no de acuerdo con la disposición constitucional, es decir respetando estrictamente el orden jurídico, sino respondiendo a la importancia per se que la ciudad de México tenía como centro político y económico y que se hizo aún más evidente con el crecimiento económico y la centralización política que caracterizaron al régimen de Diaz, quien no hizo más que retomar el esquema anterior, en que la ciudad de México tenia un lugar fundamental.

Con la "Ley de organización ..." propuesta y aprobada por el Congreso en 1903, se resolvían varios problemas y se evitaban los posibles enfrentamientos de poderes, al depender el gobierno político y administrativo de la ciudad directamente del Ejecutivo y limitar la función de los ayuntamientos a la de órganos consultivos. De esta forma, la capital y su distrito dependian para su gobierno del Ejecutivo Federal, resolviendo la incongruencia que existia con el texto constitucional, pues se sancionaba una ley que a su vez respondía a los intereses políticos del régimen.

La ley citada vino a confirmar una realidad política y económica que de tiempo atrás se había impuesto, y en esta forma el Ejecutivo centralizó aún más el poder y lo concentró en la capital

" "Ley de organización política y municipal del Distrito Federal", en Luis G. Ortíz Molina, Prontuario. Texto de los acuerdos, bandos, circulares, decretos, leyes, reglamentos y demás disposiciones vigentes de la Secretaria de Gobernación y sus dependencias, México, p. 32-72. Mexican Year Book. A statistical financial and economic annual compiled form official and other returns. Mexican Year Book, Publishing Co., 1903, p. 559-560.

7 "Ley de organización política...", artículos 18 y 19, p. 50-51. 
de la República. La decisión tomada por el Ejecutivo encabezado por Porfirio Diaz en cuanto a la ciudad de México y el Distrito Federal, reforzaba su proyecto político de contar con una capital que se gobernara, diseñara y reformara según los designios y proyectos federales.

Un objetivo sustancial de la política urbanística del régimen porfiriano fue procurar alterar la fisonomía de la ciudad de México mediante modificaciones profundas a su vieja traza y ampliar el recinto citadino. Se edifícó buscando una correspondencia entre el paisaje urbano y la imagen de "orden y progreso" que la elite porfiriana se había forjado de sí misma y de la que hiciera ostentación pública; para cumplir con tal propósito, era indispensable un sello arquitectónico marcado por la modernidad y que reflejara en diseños y formas la riqueza y la opulencia de que disfrutaban los beneficiarios del crecimiento económico.

Era una política abierta y deliberada, que no ocultaba sus intenciones y reflejaba la confianza y el optimismo imperantes. Se identificaba sustancialmente con las concepciones urbanísticas prevalecientes en las grandes ciudades metropolitanas en cuanto a las formas y espacios arquitectónicos. Uno de sus ejes era “... descentralizar los lugares de atracción, los sitios de paseo y los puntos en que se aprovisionan los negociantes, los clientes y los extranjeros ... procurando que en el conjunto de la ciudad hubiera bellos edificios, palacios suntuosos". Los nuevos diseños y su construcción, además de cambiar la faz de la ciudad, pretendían servir de estímulo y ejemplo para que la población que viviera en casas del viejo estilo, mejorara sus fachadas. ${ }^{8}$

Otro de los grandes fundamentos del cambio urbanístico porfiriano fue el de intensificar la construcción de "...calles amplias, asfaltadas y rectas que permitieran cruzar la ciudad de un extremo a otro". Su puesta en marcha trajo consigo innovaciones considerables en el plano de la ciudad, aunque conservó su impronta colonial con la preservación de un centro de edificios y monumentos coloniales, así como de calles trazadas en forma de cuadrícula regular.

Durante el auge porfiriano, un nuevo modelo de ciudad se fue edificando y supuso rebasar los viejos límites del casco urbano. La posibilidad de mutación y alteración se había iniciado desde los años de la Reforma con la política de desamortización que fracturó a la ciudad de corte colonial, al facilitar la expansión del territorio citadino fundando nuevas colonias en los que habían sido terrenos de la Iglesia, como colegios y cementerios, y en potreros y huertos de los conventos puestos en venta. ${ }^{10}$

Con el arribo de la prosperidad y la riqueza en la década de los ochenta la disponibilidad de terrenos para urbanización facilitó el levantamiento de nuevas edificaciones para habitación o negocios, inspiradas en los estilos en boga y diferentes a las viejas

\footnotetext{
${ }^{8}$ Auguste Génin. Notes sur le Mexique. Coutumes mexicaines, México, Imprenta Lacaud, 1908-1910, p. 184.

Ibid., p. 23.

${ }_{10}$ Ma. Dolores Morales, "La expansión de la ciudad de México: el caso de los fraccionamientos". en Alejandra Moreno Toscano et al. Ciudad de México. Ensayo de construcción de una historia. México, INAH, 1978, (Colección Cientifica, Historia. núm. 61), p. 194.
} 
construcciones coloniales caracterizadas -como escribía un nostálgico- por su solidez y estilo predominantemente barroco, que la presencia de iglesias, palacios, casas, puentes, fuentes y acueductos atestiguaba. ${ }^{\prime \prime}$

A finales del siglo XIX, ya era posible observar un nuevo estilo arquitectónico que convivia con el de tipo colonial. Un visitante extranjero conocedor de la ciudad de muchos años atrâs, apreciaba los cambios que veia ahora, en su visita; señalaba con entusiasmo la modernización de la arquitectura al abandonar las rutinas y tradiciones de la práctica española, cuyas construcciones se basaban en un modelo único que, si bien les daba un carácter sólido, cuadrado, con grandes estancias de techos altos, uno o varios patios, galerías como claustros, y que disponian de un gran número de alojamientos, eran en cambio poco confortables y de "una monotonía desesperante". Por el contrario, afirmaba que "hoy ... los arquitectos mexicanos han dado curso libre a su imaginación y en muchos casos los resultados son palpables". ${ }^{2}$ Las grandes avenidas, cuyo trazo se había iniciado con el Imperio cambiaron su nomenclatura a Juárez y Paseo de la Reforma; esta última era ahora una “... larga calzada que empezaba donde terminaba Juárez y llegaba hasta Chapultepec, con una extensión de tres kilómetros y medio de sauces, eucaliptos, chopos y ahuehuetes y con un ancho de sesenta metros, acera asfaltada en cada lado para el tránsito de peatones y en donde se fueron instalando estatuas representativas de los hijos más ilustres de cada estado de la federación, así como en las glorietas que la componian se erigieron estatuas como la de Cuauhtémoc y Cristóbal Colón", convirtiéndose en muestra ejemplar de las nuevas concepciones urbanísticas. $^{13}$

En esta nueva avenida se "... encuentran las construcciones más bellas, las más lujosas y del mejor estilo. 'Villas' a la italiana, 'châteaux' renacentistas, 'maisons' griegas, 'cottages' ingleses y 'bastides' marsellesas"; que recordaban a muchos visitantes extranjeros sus lugares de origen, pues se trataba de reproducir con mayor o menor fidelidad la arquitectura de esos países. ${ }^{14}$

Una descripción de la ciudad de México de 1910 nos daría la imagen de la porción moderna, de la cual formaban parte colonias como San Cosme, Juárez, Condesa y Roma, además de los alrededores del Paseo de la Reforma y de Bucareli; colonias que por su reciente edificación contaban con un sinnúmero de calles trazadas en ángulo recto que permitian cruzarlas a diestra y siniestra, flanqueadas por grandes mansiones, rodeadas a su vez de jardines que evocaban "hermosos rincones de París, Bruselas, Londres y Nueva York, gracias a su estilo parisino, flamenco, neoyorkino y bostoniano, aunque - anota el cronista-... hay que confesar que nada de esto es original". 15

$"$ J. Figueroa Domenech. Gwia general descriptiva de la Repiblica Mexicana. Historia. geografia, estadistica con triple directorio del comercio y la industria, autoridades, oficinas puiblicas, abogados, médicos, correos, telégrafos y ferrocarriles, México, Editor Ramón de S. N. Araluce, 1899, p. 100.

"2 Baron Gostkowki, De Paris a Mérico par les États Unis, Paris, PV Stock Editeur, 1899 , p. 340.

${ }_{13}$ Figueroa Domenech, op. cit., p. 159.

it Gostkowki, op. cit., p. 341 .

15 Génin, op. cil., p. 24. 
Las características arquitectónicas de la ciudad estaban geográfica y socialmente circunscritas, haciendo más palpable la diferenciación entre sus distintas partes, que también evidenciaban una forma de construir y de vivir diferentes. Las desigualdades entre riqueza y pobreza eran tangibles y se manifestaban por el lugar habitado: la vieja ciudad de raigambre colonial o las nuevas colonias.

Tan marcadas diferencias en los estilos de la ciudad no se atenuaban ni mitigaban en el casco viejo; ahora se hacía patente que a pesar de los esfuerzos para disminuirlas, se mantenian en aquella parte de la población que vivía en casas y edificios maltrechos, rodeados por calles sucias y mal pavimentadas, que en la temporada de lluvias los obligaba a andar con el lodo hasta las rodillas y esto contrastaba con que a unos cuantos pasos del centro se localizaban los grandes almacenes alumbrados profusamente con luz eléctrica. ${ }^{16}$

El contraste saltaba a los ojos de cualquiera que tuviera una visión de la ciudad en su conjunto, pues los proyectos y planes de demoler los viejos barrios y colonias para construir casas para obreros, higiénicas y confortables, quedaron en su mayoría en meras proposiciones, ${ }^{17}$ heredándose entonces una ciudad diferenciada socialmente por su traza y arquitectura.

Las diferencias sociales y culturales se extendieron a otros ámbitos. pues aparte de las colonias construidas ex profeso, según las modas dominantes, la elite hizo alarde de su distancia social partiendo de una separación cada vez más drástica, respecto al resto de la población, en la forma de divertirse, reunirse y pasear, buscando un aire más exclusivo, siendo la exclusividad un rasgo distintivo y muestra inequívoca de refinamiento.

La preocupación por la exclusividad y por rodearse de un ambiente ad hoc contribuyeron al auge de los casinos y clubes, los cuales se pusieron de moda; su carácter excluyente se garantizaba por el reducido número de los socios. El Casino Nacional, el Jockè Club, el Casino Español, el Casino Francés, se convirtieron en referencias obligadas entre hombres de la misma condición social, para reunirse a discutir, divertirse y tratar negocios en un clima distendido. Una descripción del Jockey Club nos dibuja algunas de sus características más sobresalientes: el Club estaba instalado en la Casa de los Azulejos; contaba con billares, boliche, salones para juego de cartas, un comedor atendido por un chef francés; entre sus miembros distinguidos se encuentra al entonces secretario de Hacienda, José Y. Limantour. ${ }^{18} \mathrm{El}$ ambiente que se respiraba lo sintetiza un diplomático español, asombrado durante su visita por los concurrentes, al oirlos "conversar correctamente en francés e inglés sin haber jamás salido de la República"."19

El lugar para pasear públicamente, acorde con su situación y consideración de sí mismo, se convirtió en asunto de preocupación de la elite que buscaba hacerse notoria y pública, pero donde pudiera estar entre iguales. La Alameda de finales del siglo pasado

16. Ihid., p. 184.

17 Loc. cit.

is Figueroa Domenech, op. cil., p. 155.

${ }^{14}$ M. H. Pastor. Impresiones y recuerdos de mis viajes a México, San Sebastián, España. La Voz de Guipuzcoa, 1900, p. 62. 
ilustra este anhelo cada vez más pronunciado, pues está descrita como un parque "...delicioso punto de solaz y recreo... y afortunadamente sólo acuden a él a disfrutar sus embalsamadas brisas y sus frescas sombras las clases educadas, haciéndose por ello muy agradable la estancia en aquel sitio al caer la tarde. En la avenida Juárez contigua a la Alameda, encontramos a los mismos paseantes" en "...incesante rodar de carruajes particulares que se dirigen al aristocrático paseo de la Reforma o en lenta e interminable fila regresan del mismo al anochecer". 20

La Plaza de la Constitución, por el contrario, según la retrata otro autor que no oculta sus gustos y preferencias, es un paseo "...con su hermoso bosque central y el jardín que hay frente de la catedral, sería el más encantador paseo de la ciudad, especialmente en las noches de primavera, cuando la banda de música ameniza aquel ya de por sí delicioso lugar, llenándolo de armonias, desde el alto y profusamente iluminado kiosco. Por su situación en el corazón de la capital se prestaba a la concurrencia de las familias; pero el pueblo... con desaseo habitual... lo invadía y con sus costumbres poco edificantes, lo hizo antipático a las señoras y aun a los caballeros".21

Los cambios y modernización de los medios de comunicación, en particular las vías férreas, iniciados con la restauración de la República, fueron mantenidos y continuados con particular ahínco bajo el régimen de Díaz.

Los ferrocarriles se extendieron inconteniblemente llegando a un sinnúmero de poblaciones, comunicando el país principalmente con la frontera norte e intensificando los volúmenes de transporte de mercancías hacia los Estados Unidos, desplazando así en parte a los anteriores circuitos de intercambio con Europa. La orientación de la red favoreció en forma evidente a la capital de la República, pues para las principales líneas se convirtió en paso obligado.

El lugar privilegiado de la ciudad de México en la moderna red de comunicaciones con que contaba el país, incluyendo el telégrafo y el teléfono, la consolidaron como la principal plaza para el comercio y los intermediarios comerciales, pues reducía tiempo/distancia tanto con el interior como con el extranjero, ya sea que se tratara de personas o de mercancias.

Los ferrocarriles fueron un magnifico aliado en la implantación de medidas fiscales para facilitar transacciones a menor costo y en cantidades mayores, gracias a su mayor capacidad y velocidad; podia recorrer tramos considerables del territorio nacional sin cortapisas después de ser abolido el sistema de alcabalas. Sus efectos fueron rápidos y se hicieron manifiestos en el incremento de los volúmenes de venta registrados, siendo que una parte sustancial de ésta se llevó a cabo en la capital. ${ }^{22}$

20 Figueroa Domenech. op. cit., p. 157 y 158-159.

$\because$ Ihid. p. 157.

2 Ermilo Coello Salazar, "Comercio interior" en Daniel Cosio Villegas, Historia Moderna de Mérico. El porfiriato. Vida económica. México, Editorial Hermes, 1974, vol. II. p. 739; Seminario de Historia Moderna de México, Estadísticas económicas dol Porfirialo. Flierza de Irabajo y actividad económica por sectores, México, El Colegio de México. s.f.. p. 170-171. Mexican Year Book... op. cit., 1909-1910, p. 411. 
Que la ciudad se convirtiera en el mayor recinto comercial a escala nacional, se enlazaba a la instalación de las principales casas comerciales nacionales y extranjeras para comercializar en la misma capital y redistribuir al interior del país los productos importados para uso de la agricultura, la industria y el consumo, y servir de apoyo a las exportaciones nacionales. ${ }^{23}$

El sistema de transporte urbano, como el que comunicaba la capital con las principales poblaciones del Distrito Federal y algunas del Estado de México también se modernizó. Tranvias y pequeños ferrocarriles tirados por animales, que se introdujeron al regreso de la República, utilizaron después vapor y más adelante fueron electrificados.

La red urbana periférica reprodujo en su diseño uno de los rasgos característicos de las grandes líneas de ferrocarriles al tener como centro privilegiado a la ciudad de México. Su extensión creció rápidamente. De $90 \mathrm{~km}$ existentes en 1882, pasó a 318 en 1910; es decir que triplicó su kilometraje. Según el relato de un viajero. "México es la ciudad de los tranvias... Rara es la calle por donde no pasan... y no hay arrabal ni pueblecito cercano donde no lleguen sus líneas, utilizándolos no sólo para el transporte de viajeros, sino también para el de mercancías, y hasta para los entierros, pues existen, por llamarlos asi, 'tranvías mortuorios' con sus correspondientes carros fúnebres para el duelo y comitiva.", 24

El uso del transporte público se fue haciendo una necesidad indispensable en la medida que la ciudad se expandía físicamente, acrecentando las distancias; por otro lado el encarecimiento de las rentas contribuyó a dispersar a la población que se desplazaba hacia los suburbios, más baratos. Disponer de vehículos privados se circunscribía a escasísimos núcleos de la sociedad capitalina.

La nueva situación se reflejó en la multiplicación del número de viajeros; en 1882 hubo un promedio de 10 millones de pasajeros, mientras que en 1903 viajaron diariamente 80 mil personas y en 1910 se vendieron $180 \mathrm{mil}$ boletos diarios; en días festivos o de asueto la venta suponia un monto de entre $210 \mathrm{mil} \mathrm{a} 240 \mathrm{mil}$ boletos. Si sumamos el número de boletos vendidos en 1910, año del centenario, el resultado dará la cantidad de 10 millones de viajes. $^{25}$

Contribuyó también al incremento de la densidad del tráfico de pasajeros la iriauguración de nuevas líneas, así como la creciente importancia de las localidades aledañas a la capital, debido tanto al aumento de su población, como a la mayor dispersión de las actividades económicas en la periferia...

Se fue haciendo familiar la imagen de grupos de pasajeros que iban y venian a cualquier hora de la jornada. Habitantes de colonias y pueblos circunvecinos se veían obligados a desplazarse utilizando los tranvías, por la mañana, a medio día y por la tarde para llegar a sus lugares de trabajo, para visitar a sus familiares, a sus amigos... 26

A finales del siglo pasado, la capital, al igual que otras ciudades mexicanas como Mérida, Veracruz, Guadalajara y Monterrey,

23 Coello Salazar. op. cit., p. 737.

¿t Pastor, op. cit.. p. 59. Mexican Year Book..., op. cit., 1907, p. 570.

25 Génin, op. cit., p. 282.

soc: cil. 
tuvo un aumento sustancial en el número de habitantes; la ciudad de México creció a un ritmo menor en términos relativos, aunque debe recordarse que ya era la ciudad más poblada del país y así se mantuvo; en 1895 contaba con 330 mil habitantes y en 1910 llegó a más de 470 mil. A su incremento contribuyó decisivamente la centralización y el recibir los beneficios de una economía en expansión que la convertían en uno de los polos de atracción migratoria más importante del país.

La migración explica en gran medida el crecimiento de la capital y de varias poblaciones de la periferia. El contingente más numeroso de migrantes que arribaba a la capital provenía de las localidades vecinas, aunque también los hubo de lugares distantes. El $70 \%$ de los migrantes provino de los estados del centro del país: México, Guanajuato, Hidalgo, Querétaro y Puebla; y de este porcentaje el $30 \%$ era solamente del Estado de México. En el cuadro siguiente se aprecia cómo el número de migrantes fue incrementándose e incluso rebasó al de los que declaran ser originarios de la ciudad. ${ }^{27}$

\begin{tabular}{llllll}
\hline \multicolumn{2}{c}{1985} & \multicolumn{2}{c}{1900} & \multicolumn{2}{c}{1910} \\
nativos & migrantes & nativos & migrantes & nativos & migrantes \\
174164 & 141097 & 125300 & 225815 & 216274 & 228374 \\
\hline
\end{tabular}

El aumento demográfico no fue exclusivo de la capital, sino que se extendió a las poblaciones vecinas, mostrando los primeros indicios de su incorporación futura a la ciudad.

Puede apreciarse, a escala de los municipios que componían el Distrito Federal, que en los más poblados un alto número de la población total se concentraba en la cabecera municipal; y por el contrario, otros se mantenian esencialmente rurales con una población más dispersa.

Porcentaje de la población de la municipalidad residente en la cabecera $^{28}$

1900

Tacubaya

90.9

Tacuba.

31.3

Guadalupe Hidalgo

49.8

Tlalpam

37.7

Atzcapozalco

Coyoacán

69.4

27 H. De Gortari Rabiela, "Le comportement démographique". La ville de $\mathrm{Me}$ vico et le District Fédéral; migration, économie et structure professionnelle 1895-1910. Tesis de doctorado en historia y civilización, Ecole des Hautes Études en Sciences Sociales. 1985, p. 81-118.

Is Ibid., p. 93. 
Coincide en estas estadísticas el mayor número de migrantes que llegaba a las cabeceras municipales más pobladas mientras las menos pobladas recibian un número menor. En 1910 Tacubaya contaba con un 53.1 de migrantes respecto a su población total; Tacuba con 50.3, Guadalupe Hidalgo con 44.03, Atzcapozalco con 30.56, Tlalpam 16.79 y Cuajimalpa solamente con el 6.81 .

No perdemos de vista las dificultades para analizar los comportamientos de los migrantes, como por ejemplo la diferencia entre migrantes y la de aquellos que efectuaban estancias diarias o cortas, a lo que se ha dado el nombre de movimiento pendular, entre los que se cuenta a "los indios de los alrededores de México [que] viven de la gran ciudad y son los que aprovisionan de todo lo referente a frutas, legumbres, flores, aves, pescados de río, huevos, mantequilla, queso; algunos en grupos pequeños, se contratan como domésticos. La mayoria prefiere quedarse en el campo y vivir dia con día. Desde la madrugada, se les ve llegar en grupos a la capital. Traen sus costales y huacales en sus espaldas con los productos que tratan de vender... Después de vender sus mercancías y comprar lo que a su vez necesitan [regresan]... a su poblado". 29

La migración externa, si bien no fue muy cuantiosa, era cualitativamente importante, y era en la ciudad de México donde era más palpable su presencia, signo inequivoco de su incorporación a diferentes actividades como las finanzas, la industria, los servicios y el comercio. Así, en 1895 había cerca de 9000 extranjeros y en 1910 casi 26000 , cifras que en números relativos -en comparación con el total de extranjeros residentes en el país-, significaba que el 8.3 y 22.2 respectivamente vivian en la ciudad capital. ${ }^{30}$

De todo lo anterior se pueden extraer algunas conclusiones: las referentes a las características de la urbanización a fines del siglo pasado y las implicaciones y permanencias que influyen en la situación actual de nuestra ciudad.

En cuanto al primer asunto, los rasgos fundamentales de la imagen que la ciudad nos delinea son precisos: una actividad política dirigida a que la capital, en el proyecto de centralización y concentración, tenga un papel clave. La expansión física es aún pausada y controlada, si la contemplamos con una mirada contemporánea, pero anuncia un paso más firme en los caminos que apenas se inician. La periferia es claramente la periferia, pero ya se esbozan los futuros tentáculos que se irán fortaleciendo y que borrarán décadas más tarde, en un ímpetu avasallador, toda traza y diferencia que separaba a la ciudad de sus alrededores.

La segregación social y espacial muestra cómo la ciudad puede vivirse de maneras distintas; es decir, habitar, convivir, divertirse y recorrerla, eran actividades marcadamente diferenciadas según se esté situado en la escala social. Como parte de la vida cotidiana, el transportarse en grandes grupos empieza a formar parte del escenario y a convertirse en una práctica reiterada.

En la historia de nuestra urbanización se muestran -en una revisión somera como la que hemos hecho-, grandes permanencias

$\because 9$ Génin. op. cit., p. 114.

"Moisés González Navarro, "La vida social" en Daniel Cosío Villegas, op. cit., Vida Social, p. 99-109; Patrice Gouy, Pérégrinations des Barcelonnettes au Mexique. Grenoble, Presses Universitaires de Grenoble, 1980. 
que ayudan a explicarnos el porqué de la concentración demográfica más importante de la tierra, que, vista en perspectiva, supuso también la intensificación del control sobre los recursos y la modificación brutal del entorno natural.

Para entender dicho proceso no podemos recurrir exclusivamente a explicaciones inmediatas; debemos remontarnos a analizar la alteración de la estructura rural, estrechamente ligada a las migraciones, y que gestó una ciudad que concentró cada vez más recursos, población y poder, y cuya composición hizo y ha hecho factible un modelo de urbanización desequilibrado.

En general, se acepta que durante la Reforma y el Porfiriato se construye el México moderno y que consustancial a éste está la ciudad de México, en la cual reside la fuerza y la voluntad ejecutiva, siendo esta última un actor histórico decisivo en nuestro país.

Imágenes del pasado, hoy acrecentadas, magnificadas, incontrolables aunque rescatadas del pasado, son anuncios clarividentes del futuro. Nuestra modernidad urbana se inicia incontenible por lo menos desde los tiempos de don Porfirio. 